\section{Abortion foe blamed for research head upset in Australia}

[SYDNEY] The Australian cabinet has become embroiled in controversy over allegations that a legislator with strong anti-abortion views may have helped to block the appointment of a leading candidate as chairman of the National Health and Medical Research Council (NHMRC).

Many in the medical research community have expressed anger that the post was not awarded to John Funder, a leading endocrinologist and the first nominee of the health minister, Michael Wooldridge. The position is to be taken instead by Richard Larkins, a widely respected physician at the University of Melbourne.

It is widely believed that the candidacy of Funder, who is director of the Baker Medical Research Institute in Melbourne, was undermined by Brian Harradine, one of two independents holding the balance of power in the Australian Senate.

Harradine, a conservative Roman Catholic, is a critic of abortion under the national health scheme. He is also an opponent of Wooldridge: lacked research into birth con- cabinet backing. trol, and of the so-called

'abortion pill', RU486, imports of which the government has agreed to ban at his urging. Harradine has criticized Funder - also a Catholic - for his more liberal views on these matters.

Although Funder had received a draft contract from Wooldridge's department, it was subject to cabinet approval. When this was not announced following a scheduled meeting of the cabinet, the opposition released a petition from 24 senior researchers who urged the government not to succumb to "external political factors" based on Funder's "perceived beliefs on sensitive bioethical issues".

Harradine denies he has influenced the cabinet's decision not to appoint Funder or that his religious and ethical views have been factors. But he acknowledges that he made unspecified "representations" on behalf of an unnamed voter.

Despite a pre-election commitment last year, the government has shown no enthusiasm for boosting the NHMRC's current budget of A\$150 million (US\$116 million) for peer-reviewed grants. But Larkins, showing his independence of the conservative government's agenda, seized the opportunity of his appointment to state his belief that biomedical research requires a sustained increase in public funding.

PeterPockley

\title{
Holland picks 'superleague' plan, despite criticisms
}

[PARIS] The Netherlands, ranked tenth in the world in terms of scientific output, is embarking on a reform of its research system that could lead to a 'superleague' of ten university research schools. A shake-up of NWO - the Dutch equivalent of the US National Science Foundation - and the creation of a system similar to Germany's Max Planck Institutes are also on the cards.

Under the proposed 'superleague' scheme, up to ten research schools would be chosen by NWO as centres of international excellence, on the basis of their past performance and future plans submitted in response to a call for proposals due to be issued later this year.

The superleague schools would be reserved half of the DFL200-million (US\$106-million) annual research funds provided for the country's 100 or so research schools. The research schools were set up five years ago to sharpen the focus of research at the Netherlands' 13 research universities by regrouping teams in particular disciplines.

Another reform targets NWO itself. This is at present made up of three layers. Individual research councils - such as the Fundamental Research on Matter Agency (FOM), a body roughly equivalent to Britain's former Science and Engineering Research Council - answer to an umbrella body, the Research Council for Natural Sciences, which reports to the NWO general board.

One proposal being considered would break up this umbrella body into a series of research councils for individual disciplines reporting direct to the general board. Under this plan, FOM would become the physics research council.

At present, both NWO and the Royal Netherlands Academy of Science also manage their own research institutes. But the science minister, J. M. M. Ritzen, is keen that they should cease to do so, arguing that this conflicts with their responsibility for funding university research.

The two organizations are scheduled to submit a final proposal to the government next month. In one scenario, their institutes would be combined into a system similar to the Max Planck Institutes in Germany, and would be run by a board supervised jointly by NWO and the academy.

One result could be that FOM would lose direct control of its institutes, such as those for nuclear research, nuclear fusion and freeelectron lasers. But some researchers oppose such a move. Ronald Griessen, a Swiss national who works on superconductivity at the Free University of Amsterdam, argues that it would undermine FOM's centralized system of evaluation.

In general, Dutch scientists have broadly welcomed the goals of the reforms, namely to concentrate resources, increase competition between researchers and boost the visibility of Dutch research abroad.

But many remain sceptical that these goals will be achieved by the proposed changes, which are the latest in a series of reforms by successive governments. Scientists are concerned in particular that the superleague proposal may in fact harm research.

Critics claim that selection at school level is inappropriate, arguing that this is best carried out at the level of individual groups. They also question the feasibility of comparing schools in different disciplines. They say that schools excluded from the top ten will have to compete for the remaining half of the research funds, and that this will penalize good groups at these schools and hinder the development of young universities and emerging schools.

NWO and the academy are scheduled to submit a detailed proposal to the government next month on how the superleague should operate. They are expected to recommend asking schools to submit grant applications from a few select groups rather than from the school as a whole. The winning consortia will each receive between DFL3 million and DFL 10 million a year over ten years, with a review halfway through this period

The fact that NWO - rather than the universities - will be responsible for selecting the winning schools reflects a desire to give the organization a greater say in the distribution of the universities' DFL2.6-billion research funds. Although research councils in most countries distribute 25 to 30 per cent of the budgets for university research, the Netherlands distributes only 12 per cent in this way.

Most Dutch scientists seem to agree that NWO should be given a greater say in national research spending. They argue that, with its well developed system for assessing grant proposals and its broad view of science, it is better placed than individual universities to promote open competition and coherent research strategies at national level.

Indeed some people, such as George Robillard, director of the Groningen Biomolecular Science and Biotechnology Institute, say that the DFL 100 million earmarked for the superleague might be better spent by simply transferring it to NWO, where the money could be used to expand an existing scheme - similar to the US system of Howard Hughes professorships - under which leading groups are awarded large grants for five-year periods. 